\section{Association of environment and place of birth with asthma in Chinese immigrant children}

\author{
Doug Brugge, 1 Mark Woodin,2 \\ Madhuri Indaram, ${ }^{3}$ \\ Dora Hui, 4 Michelle Pallela
}

1Tufts University School of Medicine, Department of Public Health and Family Medicine, Boston, MA; ${ }^{2}$ Tufts University School of Engineering, Department of Civil and Environmental Engineering, Medford, MA; ${ }^{3}$ Tufts University School of Arts and Sciences, Medford, MA; 4Wellesley College, Wellesley, MA, USA

\section{Abstract}

Despite the advances in perinatal and neonatal care and use of newer potent antibiotics, the incidence of neonatal sepsis remains high and the outcome is still severe. For years, investigators have sought a test or panel of tests able to identify septic neonates accurately and rapidly in order to obtain an early diagnosis and develop a specific effective treatment for a successful outcome. In addition to the standard procedures (blood, CSF, and urine cultures, chest x-ray), such panels have included a combination of total and differential cell counts, total immature neutrophil counts, immature to total neutrophil ratio, platelet counts, and levels of acute-phase reactants and cytokines. Furthermore, the science of proteomics and genomics has been applied to the search for biomarkers, production of protein profiles and genetic polymorphisms that can rapidly help the prediction, early diagnosis, and treatment of human diseases, but, for now, data are as yet insufficient to confirm their validity.

\section{Introduction}

Asthma is a common chronic illness in the United States, affecting both adults and children. In the United States alone, the prevalence of the disease nearly tripled in children, from $3.6 \%$ affected in 1980 to $9.1 \%$ in 2007.1 The illness is characterized by wheezing, coughing, chest tightness, and shortness of breath, and can be quite debilitating, especially for children. Healthcare treatments and lost work and school days due to asthma cost billions of dollars every year. ${ }^{2}$ The reasons people develop asthma are still unclear, although one possible explanation is the hygiene hypothesis. The hygiene hypothesis states that the rise in the prevalence of asthma is a result of modern sanitation. According to this perspective, children who live in unsanitary environments tend to have a lower incidence of asthma and other allergic illnesses due to childhood infections that are rare in developed countries. The infections, in turn, are thought to interact with the immune system in ways that protect against the development of asthma and other immunemediated diseases. ${ }^{3-6}$

The prevalence of asthma is high in the United States and other English speaking countries. ${ }^{7}$ In the US, asthma prevalence is highest in Puerto Ricans, African Americans, Filipino and Irish Americans, and Native Hawaiians, and lowest in Mexican and Korean Americans. ${ }^{8-10}$ Chinese Americans appear to have a higher asthma prevalence than Caucasian Americans, although the studies are quite recent.9,11,12 Our group has reported that Chinese children born in the United States have dramatically higher asthma prevalence compared to those born in China. ${ }^{13-15}$

An alternative to the hygiene hypothesis might be to interpret these studies as evidence that migration to a new environment exposes people of non-US origins to different allergens, resulting in a higher prevalence of asthma. However, most immigrants come from places with poorer sanitation and hygiene, ample exposure to allergens, and often higher levels of air pollution. We conducted the survey reported here at the South Cove Community Health Center and the Asian Clinic at Tufts Medical Center, both located in Boston Chinatown. Each of these clinics serves primarily limited English proficient immigrants. Our goal was to assess whether indicators of risk of early childhood infection might partially explain the association between being foreign-born and having diagnosed asthma. Because we could not measure prior infections directly, we asked questions about unsanitary living conditions as a surrogate for risk of infectious disease exposure.

\section{Materials and Methods}

\section{Consent/institutional review board approval}

The Tufts medical center institutional review board and the south cove community health center board of directors approved the study protocol, which was considered minimal risk. Oral consent was given by at least one parent or legal guardian, in person or, rarely, by phone. The parent(s) (and children if 11 and older) were given a one page disclosure statement in either English or Chinese at the choice of the participants. The data collected were anonymous for the purpose of the IRB, and were de-identified for the purpose of the health insurance portability and privacy act.
Correspondence: Doug Brugge, Department of Public Health and Community Medicine, Tufts University School of Medicine, 136 Harrison Ave, Boston, MA, USA. E-mail: dbrugge@aol.com

Key words: asthma, hygiene hypothesis, sanitation, effect modification, place of birth.

Acknowledgements: we gratefully thank the staff of the Asian clinic at Tufts Medical Center and the pediatrics department at south cove community health center for allowing us to recruit from their waiting rooms. We thank Sue Ponte, Vivian Tang, Amy Lin, and Alice Tin for their assistance with the study.

Contributions: DB, study design, data collection and analysis, and manuscript writing; MI, literature review and manuscript writing; DH, data collection, literature review and manuscript writing; MP, design and data collection assistance and manuscript review; MW statistical analysis and manuscript writing.

Conflict of interest: the authors report no conflicts of interest.

Received for publication: 10 January 2011.

Revision received: 1 March 2011.

Accepted for publication: 2 March 2011.

This work is licensed under a Creative Commons Attribution 3.0 License (by-nc 3.0).

(C) Copyright D. Brugge et al., 2011

Licensee PAGEPress, Italy

Pediatric Reports 2011; 3:e2

doi:10.4081/pr.2011.e2

\section{Recruitment}

Parents and legal guardians accompanying children who appeared eligible were approached ad hoc in the waiting rooms of the pediatrics department at the Floating Hospital for Children at Tufts Medical Center and the pediatric department of the South Cove Community Health Center in 2008 and 2009. In order to evaluate asthma status, a written questionnaire was administered orally in English or Chinese at the choice of the participants but also given to participants to read along. Guardians of children younger than 11 years old answered the survey for their children because young children may not be able to answer accurately. Older children answered for themselves. Any Asian in the waiting room was approached to determine eligibility. If the child was not of Chinese decent, if the child was either over 18 or under 4 or had previously completed the survey he/she was excluded.

The questionnaire consisted of 34 questions, including sex, diagnosis of asthma, allergies, and place of birth. Socioeconomic status (SES) was determined based on reported occupations of both parents, with jobs coded according to expected educational level 
required. The questionnaire also asked about the child's previous and recent living conditions, including the incidence of cockroaches and rodents, and questions about basic sanitation (see Table 1).

\section{Data management and statistical analysis}

Data were double entered into SPSS (Version 18). Non-matching entries were examined and then corrected using the original hardcopy version of the relevant questionnaire. The final sample size was 212 children after restriction to age 4 through 18 and excluding two children with no response to the asthma question. Children under four years of age were excluded because of the difficulty in accurately diagnosing asthma in this age group. We examined all variables with descriptive statistics. No major outliers or significant distributional problems were detected and work proceeded to tabular analysis. The primary outcome variable of interest was diagnosed with asthma, which was either yes or no. We examined several variables for association with the outcome variable using odds ratios and chi-square values. Of interest in this study was whether sanitation factors (Table 1) influenced the odds of having an asthma diagnosis. We also examined whether place of birth modified the effect of certain exposures. To assess this, we examined the effects of exposure variables in asthmatic/non-asthmatic children born in the US and in asthmatic/non-asthmatic children born outside the US.

\section{Results}

\section{Demographic values and asthma prevalence}

Demographic categories, familial characteristics, and clinical factors are presented in Table 2. A total of 212 subjects were analyzed. The mean age was 10.5 years (range $=4-18$ ). There were slightly more females than males (52.8\% versus $47.2 \%)$. A total of 55 (25.9\%) children were born outside the United States, almost all from mainland China (89.1\%), with none of the remaining locations having any appreciable number. Removing the people emigrating from places other than China did not affect the findings reported below (not shown). There was not a significant association between sex and being born outside the US (25 males and 30 females, $\mathrm{P}=0.22$ ). Allergies were reported in 66 children (31.3\%). A family history of asthma was reported for 32 (15.1\%) children. Living in a lower SES household was reported for 161 (75.9\%) children. Asthma was diagnosed in 59 of the 212 subjects (27.8\%).

Table 1. Responses to sanitary questions.

\begin{tabular}{lcc}
\hline Variable & $\begin{array}{c}\text { N } \\
\text { (exposed) }\end{array}$ & $\begin{array}{c}\text { N } \\
\text { (unexposed) }\end{array}$ \\
Seen intestinal worms (China) & 3 & 65 \\
Seen intestinal worms (in US) & 0 & 203 \\
\hline Diagnosed with intestinal worms & 0 & 206 \\
Treated for intestinal worms & 6 & 205 \\
\hline Farm animals in home (China) & 3 & 69 \\
Farm animals in home (in US) & 0 & 207 \\
Touched human manure (China) & 3 & 66 \\
Touched human manure (in US) & 3 & 206 \\
\hline Used outhouse (in China) & 4 & 170 \\
Used outhouse (in US) & 0 & 205 \\
\hline Dirt floors (China) & 5 & 61 \\
Dirt floors (US) & 5 & 201 \\
\hline Pests (China) & 31 & 31 \\
Pests (US) & 83 & 127 \\
\hline Smoking in the home & 66 & 146 \\
\hline
\end{tabular}

\section{Association of asthma with demo- graphic, familial, and clinical vari- ables}

Sex was not associated with an asthma diagnosis $(\mathrm{OR}=1.2$ males versus females, $\mathrm{P}=0.57$; Table 3). Age was not significantly associated with asthma diagnosis for all subjects, for younger subjects (ages 4-10), or older subjects (ages 11-18) with all p-values $>0.50$. In contrast to our previous studies, (Woodin et al., on line), place of birth was not significantly associated with asthma ( $\mathrm{OR}=1.4, \mathrm{P}=0.23$; Table 3$)$. Children born in the US were not more likely to report a family history of asthma than children born outside the US (14.6\% versus $16.4 \%$, respectively, $\mathrm{P}=0.75$ ). Allergies were significantly associated with asthma in these data $(\mathrm{OR}=2.3, \mathrm{P}=0.009)$. There was evidence that this association was modified by place of birth. In children born in the US, the OR comparing allergies to no allergies was 3.1 with $\mathrm{P}=0.001$. In children not born in the US, this OR was 0.30 with $\mathrm{P}=0.25$ (Table 3 ). The Breslow-Day test indicated significant heterogeneity between these two odds ratios $(\mathrm{P}<0.05$. $)$ Lower SES was more common in children with asthma but this association did not reach significance $(\mathrm{OR}=2.2$, $\mathrm{P}=0.13$ ), however, there was evidence that this association was modified by place of birth. In children not born in the US, lower SES had a non-significant protective association with asthma ( $\mathrm{OR}=0.40, \mathrm{P}=0.34$; Table 3 ), while for children born in the US, this association was statistically significant and in a different direction $(\mathrm{OR}=3.9, \mathrm{P}<0.05$; Table 3$)$. The BreslowDay test was significant $(\mathrm{P}<0.05)$ indicating heterogeneity between these two odds ratios. This was not the case for family history of asthma, however, which was strongly associated with asthma $(\mathrm{OR}=5.2, \mathrm{P}<0.001$; Table 3$)$, and was not significantly altered by place of birth.
Table 2. Demographics and clinical characteristics.

\begin{tabular}{lc} 
Total population & 212 \\
Age range (mean) & $4-18(10.5)$ \\
\hline Male \% & 47.2 \\
Female \% & 52.8 \\
\hline Born outside the US (N, \%) & $55(25.9)$ \\
Diagnosed asthma (N, \%) & $59(27.8)$ \\
\hline Allergies (Yes, \%) & $66(31.3)$ \\
Family history of asthma & $32(15.1)$ \\
\hline SES (Low, \%) & $161(75.9)$ \\
\hline
\end{tabular}

Table 3. Risk factors for asthma diagnosis.

\begin{tabular}{|c|c|c|c|}
\hline $\begin{array}{l}\text { Risk factor } \\
\text { (yes versus no except } \\
\text { where indicated) }\end{array}$ & OR & $\mathbf{P}$ & $\mathbf{N}$ \\
\hline Gender (male versus female) & 1.2 & 0.57 & 211 \\
\hline $\begin{array}{l}\text { Allergies } \\
\text { (subjects born in the US) }\end{array}$ & 3.1 & 0.001 & 155 \\
\hline $\begin{array}{l}\text { Allergies } \\
\text { (subjects not born in the US) }\end{array}$ & 0.30 & 0.25 & 5 \\
\hline Family history of asthma & 5.2 & $<0.001$ & 209 \\
\hline Born in the US & 1.4 & 0.23 & 212 \\
\hline Pests seen in or around home & 1.8 & 0.07 & 212 \\
\hline $\begin{array}{l}\text { SES (low versus high) } \\
\text { (subjects born in the US) }\end{array}$ & 3.9 & 0.03 & 48 \\
\hline $\begin{array}{l}\text { SES (low versus high) } \\
\text { (subjects not born in the US) }\end{array}$ & 0.40 & 0.34 & 14 \\
\hline
\end{tabular}

\section{Asthma, sanitation, and environ- mental factors}

Almost no mothers reported smoking during pregnancy (2 out of 212) making meaningful analysis of this variable impossible. There was no significant association between smoking in the home and asthma in a child either in the 
combined data or in data stratified by place of birth ( $\mathrm{P}>0.40$ for both analyses). Exposure to any home pests showed a weak association with asthma ( $\mathrm{OR}=1.8, \mathrm{P}=0.07$; Table 3$)$. Small numbers prevented us from performing a full analysis stratified by place of birth.

We examined sanitation variables for possible association with asthma, but most odds ratio were close to 1.0 and all $\mathrm{P}$ values were $>0.10$. The primary analytical issue for all of these variables was very small numbers of subjects reporting exposure (Table 1).

\section{Discussion}

This study was conducted because our earlier studies found that foreign-born Chinese children have a lower prevalence of asthma compared to those born in the United States. As a result, we hypothesized that risk factors for early childhood infections, (measured as reported), and exposure to poor basic sanitation (which does not occur frequently in the United States), would have a protective affect against asthma. In order to test our hypothesis, we conducted a survey that asked patients at local Chinese clinics about early life childhood infections and sanitary conditions.

Unexpectedly, we did not find an association of nativity with asthma in this data set. This is in contrast to our previous studies that found such as association.13-15 It is possible that changes in sanitation in China, which has pulled hundreds of millions of people out of poverty, or shifts in the demographics of Chinese immigrants coming to the Boston area are responsible for this. To test this we examined trends in ORs from our previous studies over time using stratified tables and the Breslow-Day test for homegeneity of odds ratios. We found that, across our prior studies, ${ }^{15}$ the Breslow-Day test was non-significant ( $>>0.10)$ suggesting that effect modification by date of study was not occurring. Nevertheless, given the strength of the association between being born in the US versus not in our previous studies, the lack of association found in this study warrants further investigation. Given the lack of a temporal trend, and the robust associations we saw in a much larger pooled data set, ${ }^{15}$ we suggest that our finding of no association is most likely caused by chance in this data set with a relatively small sample size.

We found that very few of our respondents reported unsanitary conditions at their homes in China or the US, except for pest infestation, which was common. There are two possible reasons for this result. It could be that respon- dents to our survey experienced very few unsanitary conditions. If so, the findings conflict with our hypothesis that prior exposure to unsanitary conditions are prevalent enough in this immigrant population to result in frequent early childhood infections, such as helminthes, that are rare in the US. Alterna tively, since our subjects were surveyed in a public waiting room, there could have been under-reporting due to embarrassment on their part to admit to unsanitary conditions.

Interestingly, while we found no association between asthma and native or foreign birth, we did find that there was effect modification for allergies and SES with regard to asthma and nativity. The effect modification reported here is similar to our previous study. In that study we found effect modification for pests and SES, whereas there was not effect modification for family history of asthma or allergies. ${ }^{15}$ In this paper, we report effect modification for SES and allergies, but not for family history of asthma. We were unable to test for effect modification for pests in the current data set due to low numbers. Thus, the only inconsistency between the two papers was finding effect modification for allergies in this paper, but not the earlier one. This inconsistency could be due to the low accuracy of selfreported allergies.

There are numerous limitations to our study. This study relied on self-reported data which contains the potential for inaccurate reporting by respondents, something that might have been a particular problem for the sanitation questions. In addition, our sample size was small which, together with low response rates for some items, notably the sanitation questions, rendered meaningful statistical analysis virtually impossible. Further, because we recruited a convenience sample from clinic waiting rooms, the study population should not be considered representative of the Chinese immigrant population in Boston or the US. Nevertheless, the sample should be considered adequate for the exploratory associational analysis that we presented here.

There is a need for studies that can determine why many studies report lower asthma in foreign-born children. Understanding this effect might help us learn how to prevent asthma from developing.

\section{References}

1. Center for Disease Control. Asthma's impact on children and adolescents. 2009; available at http://www.cdc.gov/nchs/fastats/asthma.htm.
2. Kamble S, Bharma M. Incremental direct expenditure of treating asthma in the United States. J Asthma 2009;46:73-80.

3. Wills-Karp M, Santeliz J, Karp CL. The germless theory of allergic disease: Revisiting the hygiene hypothesis. Nat Rev Immunol 2001;1:69-75.

4. Umetsu DT, Akbari 0, DeKruyff RH. Regulatory T cells control the development of allergic disease and asthma. J Allergy Clin Immunol 2003;112:480-7.

5. Guarner F, Bourdet-Sicard R, Brandztzaeg $P$, et al. Mechanisms of disease: the hygiene hypothesis revisited. Nat Clin Pract Gastroenterol Hepatol 2006;3:275-84.

6. Rouse BT. Regulatory T cells in health and disease. J Intern Med 2007;262:78-95.

7. International Study of Asthma and Allergies in Childhood. Worldwide variation in prevalence of symptoms of asthma, allergic rhinoconjunctivitis, and atopic eczema: ISAAC. The Lancet 1998;351: 1225-32.

8. Akinbami L, Flores G, Morgenstern H. Heterogeneity of childhood asthma among Hispanic children: Puerto Rican children bear a disproportionate burden. Pediatrics 2006;117:43-53.

9. Davis AM, Kreutzer R, Lipsett M, et al. Asthma prevalence in Hispanic and Asian ethnic subgroups: Results from the California Healthy Kids Survey. Pediatrics 2006;118:363-70.

10. Johnson DB, Oyama N, LeMarchand L,Wilkens L. Native Hawaiians mortality, morbidity, and lifestyle: comparing data from 1982, 1990, and 2000. Pac Health Dialog 2004;11:120-30.

11. Lee T, Brugge D, Francis C, Fisher 0 . Asthma prevalence among inner-city Asian American school children. Public Health Reports 2003;118:215-220.

12. Claudio L, Stingone JA, Godbold J. Prevalence of childhood asthma in urban communities: The impact of ethnicity and income. Ann Epidemiology 2006;16:332340.

13. Greenfield R0, Lee AC, Tang R, Brugge D. Screening for asthma in Cantonese-speaking immigrant children. BMC Public Health 2005;5:48.

14. Brugge D, Lee AC, Woodin M, Rioux C. Native and foreign born as predictors of pediatric asthma in an Asian immigrant population: a cross sectional survey. Environmental Health 2007;6:13.

15. Woodin M, Tin AH, Moy S, et al. Lessons for primary prevention of asthma: foreignborn children have less association of SES and pests with asthma diagnosis. J Immigr Minor Health 2010; Epub ahead of print. 